\title{
Assessing Vegetation Dynamics Over Mainland Australia With Metop ASCAT
}

\author{
Mariette Vreugdenhil, Sebastian Hahn, Thomas Melzer, Bernhard Bauer-Marschallinger, Christoph Reimer, \\ Wouter Arnoud Dorigo, and Wolfgang Wagner, Senior Member, IEEE
}

\begin{abstract}
Recently, the slope and curvature estimation of the backscatter-incidence angle relationship within the TU Wien retrieval algorithm has been improved. Where previously only climatologies of the slope and curvature parameters were available, i.e., one value for every day of year, slope and curvature are now calculated for every day. This enables the retrieval of time series of vegetation optical depth $\left(\tau_{a}\right)$ from backscatter observations. This study demonstrates the ability to detect interannual variability in vegetation dynamics using $\tau_{a}$ derived from backscatter provided by the advanced scatterometer on-board Metop-A. $\tau_{a}$ time series over Australia for the period 2007-2014 are compared to leaf area index (LAI) from SPOT-VEGETATION by calculating the rank correlation coefficient $\left(r_{s}\right)$ for original time series and anomalies. High values for $r_{s}$ are found over bare soil and sparse vegetation in central Australia with median $r_{s}$ values of 0.78 and 0.58 , respectively. Forests and ephemeral lakes and rivers impact the retrieval of $\tau_{a}$, and the negative values for $r_{s}$ are found in these areas. Looking at the annual averages of $\tau_{a}$, LAI, and surface soil moisture, significantly high values are found for the anomalously wet years 2010 and 2011. Patterns in the increased $\tau_{a}$ correspond to regions with increased soil moisture and LAI. Values for $\tau_{a}$ and LAI are anomalous especially in sparsely vegetated regions, where the flush of grasses increases $\tau_{a}$ and LAI. Regions with enough precipitation and higher woody vegetation component show a smaller increase in 2010 and 2011. This study demonstrates the skill of $\tau_{a}$, and subsequently of scatterometers, to monitor the vegetation dynamics thanks to the multiincidence angle observation capability.
\end{abstract}

Index Terms-Precipitation, scatterometer, soil moisture, vegetation.

\section{INTRODUCTION}

$\mathbf{S}$ CATTEROMETERS provide backscatter observations, which can be used to monitor various ocean and land surface processes. Originally designed to monitor ocean winds,

Manuscript received June 30, 2016; revised August 23, 2016 and September 19, 2016; accepted October 7, 2016. This work was supported in part by the Austrian Science Funds FWF as part of the Doctoral Programme on Water Resource Systems (DK-plus W1219-N22) and in part by the Satellite Application Facility supporting the operational hydrology and water management (H-SAF). The work of W. A. Dorigo was supported by the personal Grant "TU Wien Wissenschaftspreis 2015." The SPOT-VGT LAI dataset was generated by the land service of Copernicus, the Earth Observation Programme of the European Commission. The research leading to the current version of the product has received funding from various European commission research and technical development programs. (Corresponding author: Mariette Vreugdenhil.)

The authors are with the Department of Geodesy and Geoinformation, Vienna University of Technology, Vienna 1040, Austria (e-mail: mariette. vreugdenhil@geo.tuwien.ac.at; sebastian.hahn@geo.tuwien.ac.at; thomas. melzer@geo.tuwien.ac.at; bernhard.bauermarschallinger@geo.tuwien.ac.at; christoph.reimer@geo.tuwien.ac.at; wouter.dorigo@tuwien.ac.at; wolfgang. wagner@geo.tuwien.ac.at).

Color versions of one or more of the figures in this paper are available online at http://ieeexplore.ieee.org.

Digital Object Identifier 10.1109/JSTARS.2016.2618838

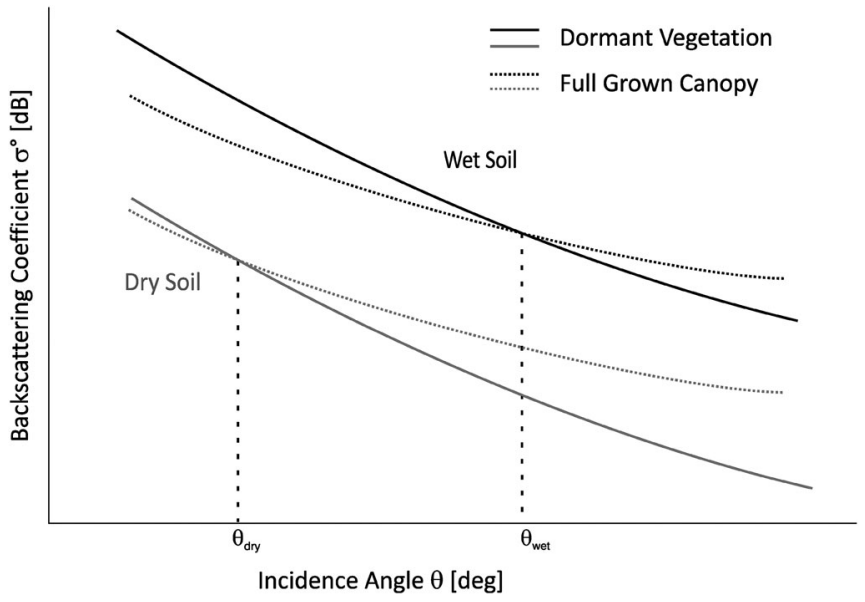

Fig. 1. Conceptual relation between backscatter and incidence angle with relation to soil moisture and vegetation (taken from [10]).

scatterometers are now also used for the retrieval of surface soil moisture and vegetation dynamics. In the late 1990s, an algorithm was developed based on a change detection method, the TU Wien algorithm, to retrieve the surface soil moisture from backscatter observations $\left(\sigma^{\circ}\right)$. The algorithm makes use of the capability of scatterometers to observe a target under a range of incidence angles $(\theta)$ [2]. The algorithm was first applied to the ERS- 1 active microwave instrument, and later to the advanced scatterometer on-board Metop-A (ASCAT-A). The dependence of $\sigma^{\circ}$ on $\theta$, the function $\sigma^{\circ}(\theta)$, can be modeled as a secondorder polynomial. The slope $\left(\sigma^{\prime}\right)$ and the curvature $\left(\sigma^{\prime \prime}\right)$ of the function $\sigma^{\circ}(\theta)$ are sensitive to vegetation dynamics; an increase in vegetation increases the $\sigma^{\prime}$ of the function $\sigma^{\circ}(\theta)$, whereas bare soils result in a lower $\sigma^{\prime}$, as shown conceptually in Fig. 1 . Within the TU Wien algorithm, $\sigma^{\prime}$ and $\sigma^{\prime \prime}$ are used to normalize all backscatter measurements to a reference incidence angle $\left(\theta_{r}\right)$ and to correct for vegetation. As a heritage of the limited number of yearly observations available from ERS- $1, \sigma^{\prime}$ and $\sigma^{\prime \prime}$ were calculated by considering all observations of the measurement period, in order to account for noise and ensure a full range of incidence angles. However, with the increasing amount of observations available on a yearly basis for ASCAT-A, Melzer [1] recently demonstrated the feasibility of calculating $\sigma^{\prime}$ and $\sigma^{\prime \prime}$ for each year individually. With this improved method, interannual variations in $\sigma^{\prime}$ and $\sigma^{\prime \prime}$ can be investigated. Hahn et al. [3] (submitted in this issue) tested the robustness and performance of the new calculation method on a global scale by comparing $\sigma^{\prime}$ and $\sigma^{\prime \prime}$ calculated from ASCAT observations from MetopA and Metop-B (ASCAT-B) independently. Their results show

1939-1404 ( 2016 IEEE. Personal use is permitted, but republication/redistribution requires IEEE permission.

See http://www.ieee.org/publications standards/publications/rights/index.html for more information. 
a good agreement between observations from ASCAT-A and ASCAT-B. Only in areas with little slope variation, i.e., deserts and tropical forests, low correlations are found because of small signal variation. In sandy deserts, high azimuthal anisotropy in combination with low backscatter leads to unreliable slope calculations. Both ASCAT-A and ASCAT-B showed seasonal variation in $\sigma^{\prime}$, with low values (steep slope) in winter time and higher values (moderate slope) in summer. The study demonstrated that the interannual variations in $\sigma^{\prime}$ and $\sigma^{\prime \prime}$ are stable and that the variability in both parameters describe real physical changes. Based on the previous studies [2], [4], [5], these variations are hypothesized to be linked to vegetation dynamics.

Wagner et al. [2] compared $\sigma^{\prime}$ retrieved from ERS-1 backscatter observations to normalized difference vegetation index (NDVI) over Spain. They found that $\sigma^{\prime}$ was not related to vegetation greenness but more strongly related to seasonal dynamics in the wet biomass of the vegetation. Recently, Vreugdenhil et al. [4] retrieved vegetation optical depth $\left(\tau_{a}\right)$ from ASCAT-A backscatter observations using $\sigma^{\prime}$ and $\sigma^{\prime \prime}$ from the TU Wien algorithm and a simple water-cloud model [6]. With this model, the temporal variation in $\tau_{a}$ is entirely controlled by temporal variations in $\sigma^{\prime}$ and $\sigma^{\prime \prime}$. Given that the only climatological values of $\sigma^{\prime}$ and $\sigma^{\prime \prime}$ were calculated, until now only climatologies of $\tau_{a}$ could be retrieved. It was demonstrated that the climatologies of $\tau_{a}$ satisfactorily follow global vegetation patterns and dynamics, as observed in leaf area index (LAI) and vegetation optical depth retrieved from passive microwave observations $\left(\tau_{p}\right)$ [4]. The novel calculation of $\sigma^{\prime}$ and $\sigma^{\prime \prime}$ for each year individually enables the retrieval of time series of $\tau_{a}$. This provides, for the first time, an opportunity to investigate the interannual variations observed in $\tau_{a}$. Vegetation is one of the important links in the water, energy, and carbon cycle, making monitoring interannual dynamics and trends in vegetation pivotal. Recently, dryland biomass was found to be an important driver of interannual variability of the carbon cycle [7]. Global change affects vegetation dynamics, for example, by an earlier onset of vegetation activity in spring due to increasing temperatures [8], but vegetation can also influence climate through, e.g., photosynthesis and albedo [9]. The availability of additional vegetation datasets from active microwave remote sensing can help monitor dynamics in the total water content of the vegetation, which can improve our understanding on vegetation dynamics and its link to the water, energy, and carbon cycle.

In this study, we extend the work reported by Hahn et al. [3] and Vreugdenhil et al. [4]: Our main objective is to assess whether $\tau_{a}$, and thus $\sigma^{\prime}$ and $\sigma^{\prime \prime}$, are sensitive to interannual variability in vegetation dynamics. First, time series of $\tau_{a}$ are compared to LAI retrieved from SPOT-VEGETATION (SPOT-VGT) observations and discussed in relation to the respective land cover classes (see Fig. 2). This is done for both the original time series and the anomalies. By subtracting the climatology from the signal, we can assess whether the interannual vegetation variability, as described by LAI, is captured by $\tau_{a}$. As described by Hahn et al. [3], the calculation of $\sigma^{\prime}$ is problematic over sandy deserts due to azimuthal anisotropy, and small variation in the signal is found in tropical forests and other deserts. Therefore, we selected mainland Australia to perform

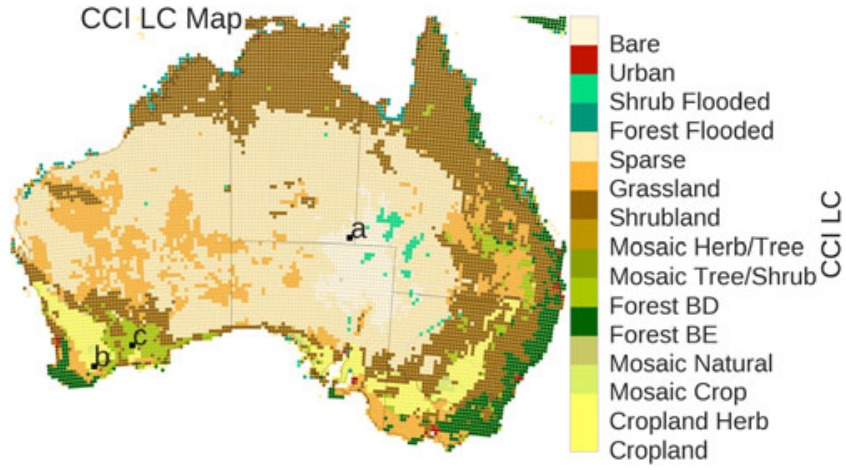

Fig. 2. Land cover map based on the European space agency's climate change initiative land cover map of 2010. The map includes the location of the time series plots from Fig. 6.

the thorough quality assessment of $\tau_{a}$. Australia is characterized by an arid to semi-arid climate in its interior and subtropical climate in the north, providing a large range of climate and land cover conditions (see Fig. 2). Furthermore, Australia experienced one of the worst droughts on record from 2001 to 2009, the so-called Millenium Drought. This was followed in 2010 by the highest spring rainfall on record in eastern Australia. Australia, with its lack of mountain ranges, semiarid climate, and location between the Antarctic, Pacific, and Indian Ocean, is especially sensitive to climate modes, e.g., El Niño southern oscillation (ENSO), Indian Ocean dipole (IOD), and southern annular mode (SAM). In 2010, all three climate modes were in a phase generally linked to wet conditions for Australia, bringing particularly large amounts of rainfall to northern and eastern Australia; a negative IOD event co-occurred with La Niña and a positive SAM [11]. On the other hand, 2010 was the driest year on record in south-west Australia (SWA), which is assumed to be less affected by ENSO [12]. Consequently, there have been important changes in vegetation in the last decade over the whole continent. The high interannual variability in precipitation combined with the large range of surface conditions and land cover makes Australia a perfect region to study the sensitivity of $\tau_{a}$ to interannual variability in vegetation dynamics. To investigate the sensitivity of $\tau_{a}$ to these extreme events, spatial patterns of annual mean values of $\tau_{a}, \mathrm{LAI}$, and surface soil moisture (SSM) from ASCAT-A observations are qualitatively analyzed. Since $\tau_{a}$ is sensitive to total water content of the vegetation and thus above ground biomass, we expect to see a significant increase in $\tau_{a}$ in eastern Australia in 2010 and 2011.

\section{DATA}

\section{A. Metop-A ASCAT Vegetation Optical Depth $\left(\tau_{a}\right)$ and Surface Soil Moisture}

For this study, $\tau_{a}$ is derived from model parameters from the TU Wien soil moisture retrieval algorithm using ASCATA observations [4]. ASCAT-A orbits the Earth since 2007 and provides C-Band observations on a global scale every two days. Within the TU Wien algorithm, we use ASCAT-A observations resampled to a 12.5-km discrete global grid [10]. Backscatter 
measurements $\left(\sigma^{\circ}\right)$ from ASCAT-A are obtained under different incidence angles $(\theta)$ and the dependence of $\sigma^{\circ}$ on $\theta$ can be modeled by a second-order polynomial. As described in Section I, $\sigma^{\prime}$ and $\sigma^{\prime \prime}$ of the function $\sigma^{\circ}(\theta)$ are sensitive to vegetation dynamics and are used to normalize backscatter $\left(\sigma_{r}^{\circ}\right)$ to a reference $\theta_{r}$ of $40^{\circ}$ and to correct for vegetation. The change detection approach calculates SSM by scaling $\sigma_{r}^{\circ}$ between the historically lowest and highest observed backscatter, the socalled dry and wet reference, respectively, which represents the driest and wettest conditions. As can be seen in Fig. 1, crossover angles exist, where vegetation effects on the backscatter are cancelled out. The wet reference is estimated by taking the average of the highest $10 \%$ of the backscatter at the wet crossover angle $\theta=40^{\circ}$ excluding outliers. Consequently, the wet reference is a constant value. The lowest backscatter is estimated at $\theta=25^{\circ}$ (see Fig. 1) and is converted back to the reference $\theta_{r}$ of $40^{\circ}$ using $\sigma^{\prime}$ and $\sigma^{\prime \prime}$. Hence, the variability in the dry reference is controlled by $\sigma^{\prime}$ and $\sigma^{\prime \prime}$ and intrinsically corrects for vegetation. Previously, $\sigma^{\prime}$ and $\sigma^{\prime \prime}$ were averaged over several years. Subsequently, the dry reference was only available as a function of the day of year, i.e., only 366 values were computed. Recently, the method to estimate $\sigma^{\prime}$ and $\sigma^{\prime \prime}$ was improved by Melzer [1]. By using a kernel smoother (or weighted linear regression scheme), $\sigma^{\prime}$ and $\sigma^{\prime \prime}$ are calculated for every single day. A detailed description of the kernel smoother is given in [3]. Vreugdenhil et al. [4] used the dry and wet reference and a water-cloud model [6] to derive $\tau_{a}$. Consequently, only climatologies of $\tau_{a}$ could be retrieved, i.e., 366 values. Using the novel calculation of $\sigma^{\prime}$ and $\sigma^{\prime \prime}$, the dry reference is available for every day, making the retrieval of $\tau_{a}$ for every day possible. $\tau_{a}$ is calculated as follows:

$$
\tau_{a}=\frac{\cos \theta}{2} \ln \frac{\Delta \sigma_{s}^{\circ}}{\Delta \sigma^{\circ}}
$$

where $\Delta \sigma^{\circ}$, in $\mathrm{m}^{2} / \mathrm{m}^{2}$, is the difference between the dry and wet reference. $\Delta \sigma_{s}^{\circ}$, also in the linear domain, represents the maximum range in backscatter values over bare soils related to a change in soil moisture only and is assumed to be constant through time. A change in $\Delta \sigma_{s}^{\circ}$ only affects the mean value of $\tau_{a}$. The temporal variation in $\tau_{a}$ is solely controlled by temporal variability in the dry reference, which is a function of $\sigma^{\prime}$ and $\sigma^{\prime \prime}$. The daily calculation of $\sigma^{\prime}$ and $\sigma^{\prime \prime}$ makes it possible to compare time series of $\tau_{a}$ with other vegetation products and investigate the interannual variability.

SSM is calculated by scaling backscatter between the historically lowest (dry reference) and highest (wet reference) observed backscatter at a location. Vegetation dynamics are corrected for within the dry reference. Due to the scaling, SSM is available expressed in relative units of degree of saturation (\%). As for $\tau_{a}, \mathrm{SSM}$ is available on a discrete global grid with a grid spacing of $12.5 \mathrm{~km}$. For this study, both $\tau_{a}$ and SSM are resampled to a $0.25^{\circ}$ grid.

\section{B. Leaf Area Index}

LAI describes half the developed area of photosynthetically active elements of the vegetation per unit horizontal ground area. GEOV1 LAI derived from visible and near infrared observations provided by the SPOT-VGT is used for this study [13]. GEOV1 LAI is derived with a neural network, using a training dataset based on CYCLOPES v3.1 and MODIS C5 LAI to relate the top of canopy reflectance to the best estimate of LAI. LAI is available globally as a ten-day composite with a spatial resolution of $1 / 112^{\circ}$. For this study, LAI is resampled to a $0.25^{\circ}$ grid.

\section{METHODS}

To validate the performance of $\tau_{a}$ over Australia, we first compare it to LAI observations from SPOT-VGT over the period 2007-2014. For this, all datasets are spatially resampled to a $0.25^{\circ}$ grid and temporally resampled to monthly averages. For every $0.25^{\circ}$ grid point in Australia, Spearman rank correlation is calculated for both original data $\left(r_{s}\right)$ and anomalies $\left(r_{s a}\right)$ of $\tau_{a}$ and LAI. Anomalies are calculated by subtracting the climatology from the monthly mean values. For further analysis, grid points with a $r_{s}$ lower than 0.2 are excluded. Since a lag was observed between the climatologies of LAI and $\tau_{a}$ [4], we calculated $r_{s}$ for different time lags of $\tau_{a}$. A map of monthly lag values is calculated by finding for every grid point the lag associated with the maximum $r_{s}$ for that point. Finally, an assessment of the spatial patterns of $\tau_{a}$, LAI, and SSM over the 2010 and 2011 La Niña phase is performed. To confirm if a significant increase occurs in a grid point for any of the three products, we check if the yearly mean of the 2010 and 2011 event is consistent with the ensemble of the yearly means during weak and neutral climate mode phases. We consider an increase to be significant when the mean over 2010 and 2011 is bigger than the ensemble mean plus three standard deviations of the ensemble mean. Since the ENSO cycles usually start in April/May of the first year and finishes the following year in March/April, the base for the yearly mean calculation is set in April. Spatially, $\tau_{a}$ varies strongly over Australia because of the large range of climates and vegetation types, from deserts in central Australia to tropical forests in the north. At each grid point, each time series is normalized by subtracting the mean and dividing by the standard deviation, both estimated over the entire period 2007-2014. The resulting normalized time series facilitate the interpretation of patterns where mean and variance vary strongly from grid point to grid point.

\section{RESULTS AND DISCUSSION}

\section{A. Quality Assessment of $\tau_{a}$}

Figs. 3 and 4 show $r_{s}$ and $r_{\text {sa }}$ per grid point over mainland Australia. In general, LAI and $\tau_{a}$ show similar temporal dynamics, which are demonstrated by an average continental $r_{s}$ of 0.46 (including negative values). For $71 \%$ of the grid points, $r_{s}$ is higher than 0.2. Even though Hahn et al. [3] found unstable retrievals of $\sigma^{\prime}$ over deserts, e.g., Sahara and Takla Makan, the highest values of $r_{s}$ are found over bare soils and sparse vegetation (see Fig. 5) with a median $r_{s}$ of 0.78 and 0.58 , respectively. Fig. 6(a) and (b), for example, time series for interior Australia, shows that in this region there is no clear seasonal cycle in $\tau_{a}$, but a clear interannual variability is found, where the highest monthly means are found in 2010 and 2011. The interannual 


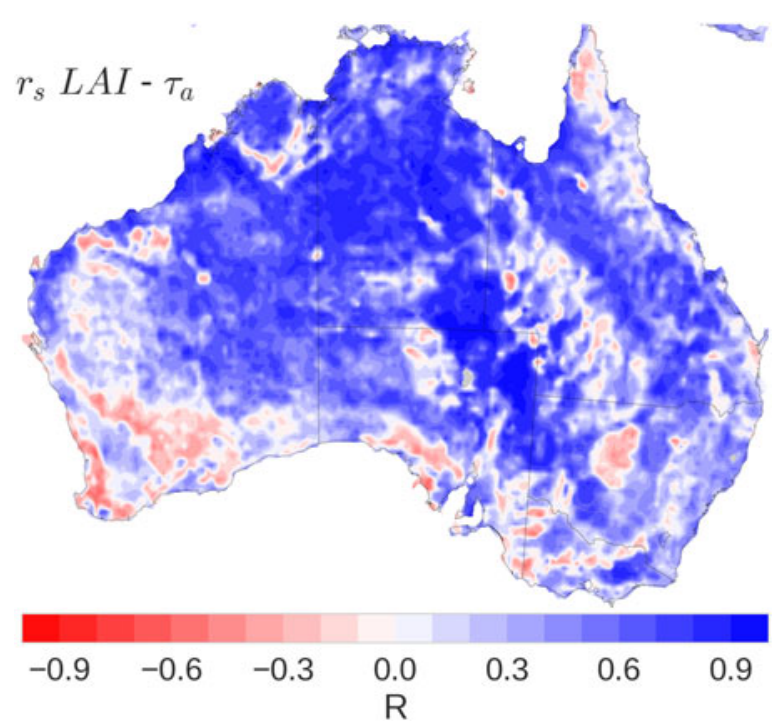

Fig. 3. Spearman rank correlation between LAI from SPOT-VGT and $\tau_{a}$ from ASCAT-A.

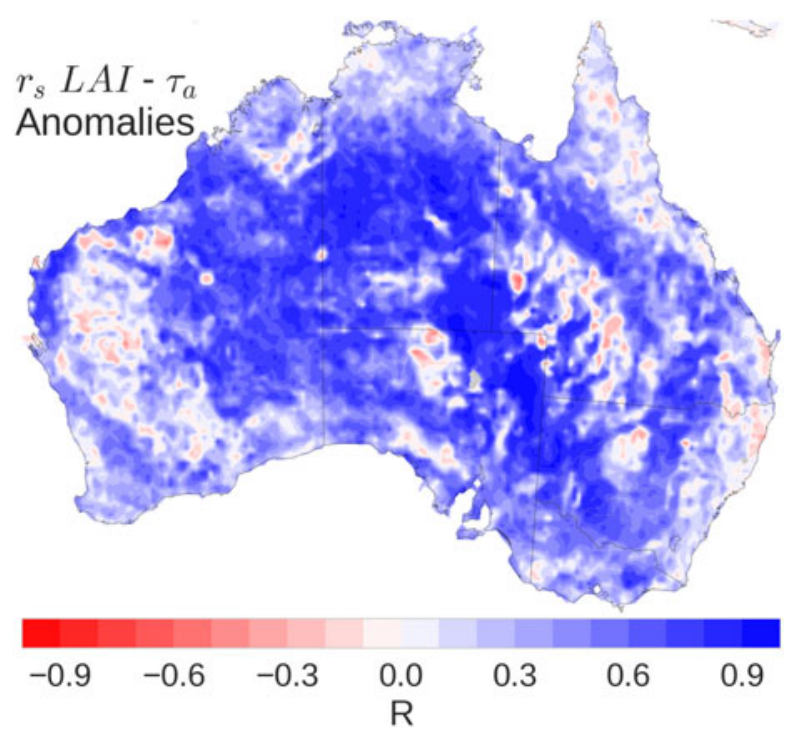

Fig. 4. Spearman rank correlation between anomalies from LAI from SPOTVGT and $\tau_{a}$ from ASCAT-A.

variability in deserts is also captured by the anomalies in $\tau_{a}$, where the median $r_{\mathrm{sa}}$ is 0.68 and 0.58 for bare soils and sparse vegetation, respectively. Shrubland and grassland show lower values of $r_{s}$, with medians of 0.35 and 0.37 , respectively. Only on ephemeral lakes and salt pans, e.g., Lake Eyre, $\tau_{a}$ does not follow LAI, which is expected due to effects stemming from open water and salt pans. Radar observations over open water are sensitive to the direction of winds and the waves on the water surface. In this case, $\sigma^{\prime}$ of function $\sigma^{\circ}(\theta)$ is strongly affected by standing water but not by vegetation.

Over croplands in New South Wales, relatively high values of $r_{s}$ are found, but lower values are observed in Western Australia, leading to a median $r_{s}$ of 0.32. Fig. 6(c) shows time series over croplands east of Perth, where a strong seasonal cycle can be observed in $\tau_{a}$, with little interannual variability [see Fig. 6(d)].

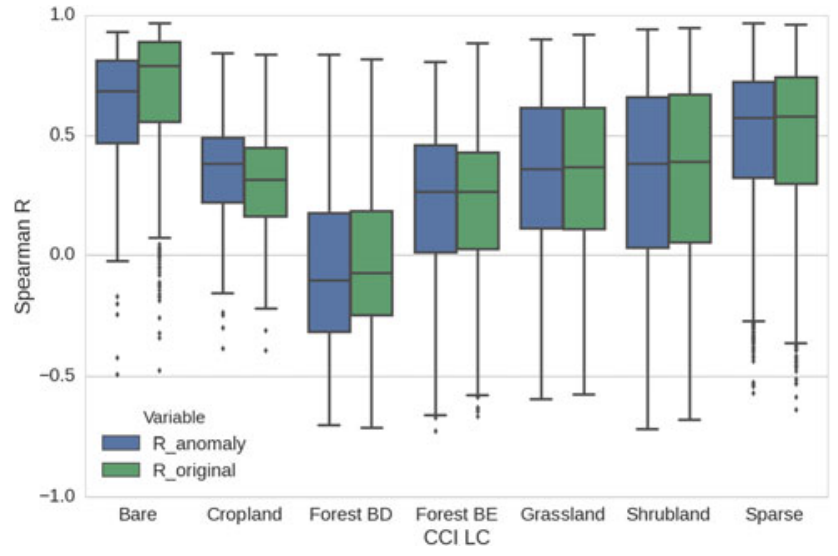

Fig. 5. Spearman rank correlation between LAI and $\tau_{a}$ for original time series and anomalies grouped per CCI land cover class.

Only in the winter of 2010, relatively low values for $\tau_{a}$ can be observed compared to other years. This can be explained by the exceptionally dry year that western Australia experienced [12]. In the forested areas surrounding the agricultural regions near Perth, a quick shift to negative $r_{s}$ values can be observed (see Figs. 3 and 4). The opposite behavior of $\tau_{a}$ with regard to LAI can also be observed in Fig. 6(e). Variation in $\tau_{a}$ is small, but a clear seasonality can be found in the monthly time series. This indicates that there is a physical process, with a clear seasonality, which causes the opposite behavior of $\tau_{a}$ compared to LAI. These negative values are found in deciduous broadleaf forests (see Forest BD in Fig. 5). A possible explanation for the negative correlation with LAI could be the increase in double-bounce scattering between the soil and the stems and trunks when leaves have fallen. Since the current model does not take into account double-bounce scattering, this is currently interpreted as an increase in $\tau_{a}$. Leaf fall has a strong seasonal cycle, which can also be seen in the $\tau_{a}$ signal over deciduous broadleaf forests (Fig. 6(f)), suggesting a natural process causing the negative correlations.

In southwest Queensland and northwest New South Wales, Channel Country, areas with negative values for $r_{s}$ are observed in flooded shrubland (see Fig. 2). The Channel Country river systems are some of the most variable and unpredictable flow regimes in the world [14]. Episodic floods can occur during summer monsoons in Northern Australia and this water can fill up the anastomosing rivers in the extensive floodplain system and stay for weeks. On the other hand, there are long periods of no flow, the floodplains are dry and the little water that is available can only be found in waterholes. Also, here, the presence of standing water is likely to affect the estimation of $\sigma^{\prime}$ and consequently $\tau_{a}$.

Fig. 7 shows the lag in months between $\tau_{a}$ and LAI, where the negative values (red colors) indicate that $\tau_{a}$ lags behind LAI. Clear spatial patterns can be observed in the lag, which correspond greatly to land cover. No lag is found for bare soils, sparsely vegetated areas, and grasslands. The high values found for $r_{s}$ and no lag indicates that $\tau_{a}$ is sensitive to similar vegetation dynamics, as observed in LAI. A clear lag can be seen between $\tau_{a}$ and LAI in croplands, with a lag of one to two 


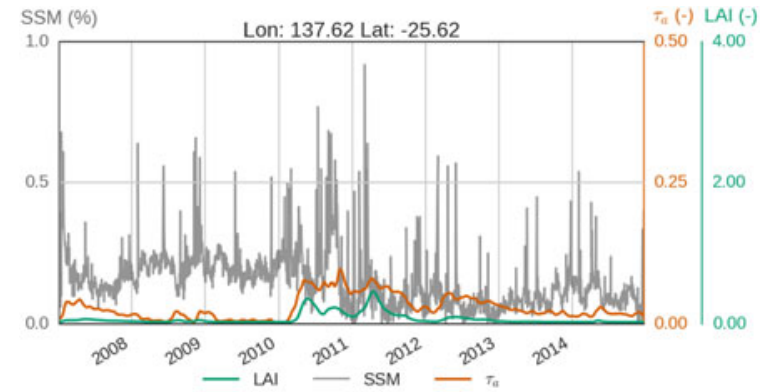

(a)

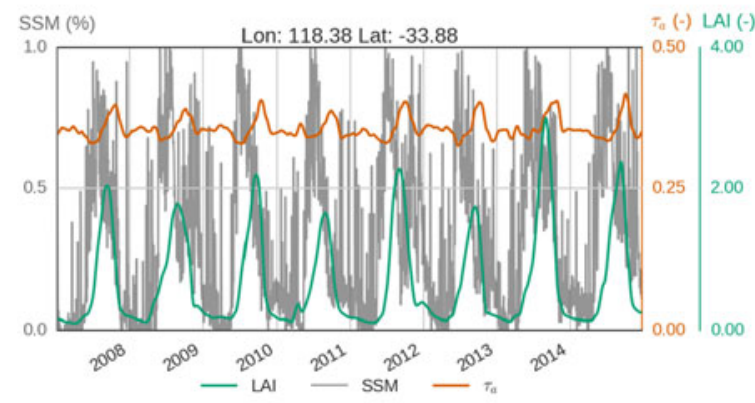

(c)

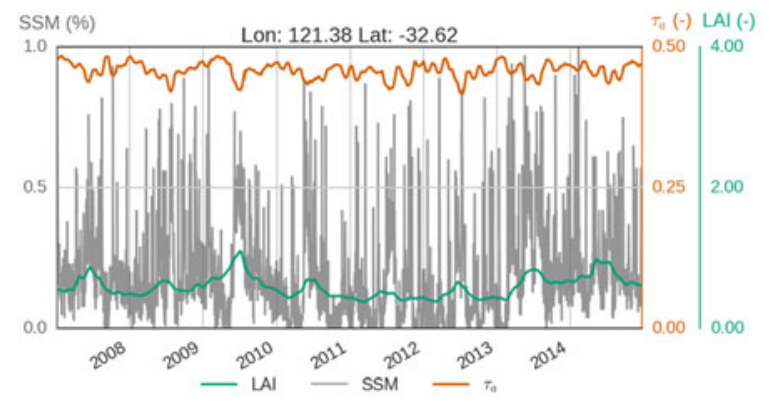

(e)

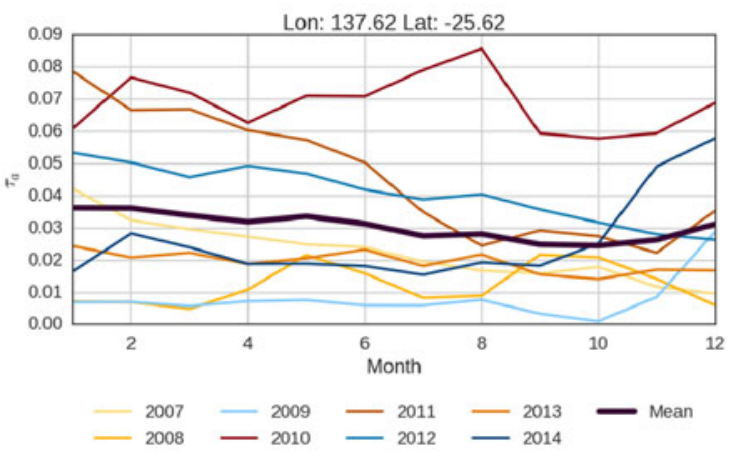

(b)

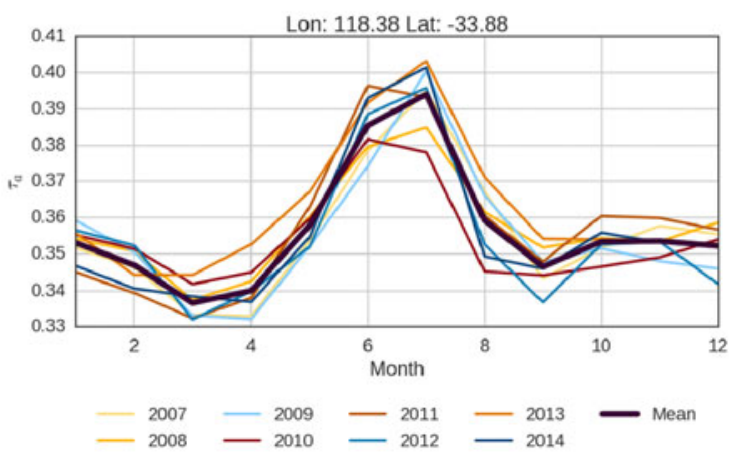

(d)

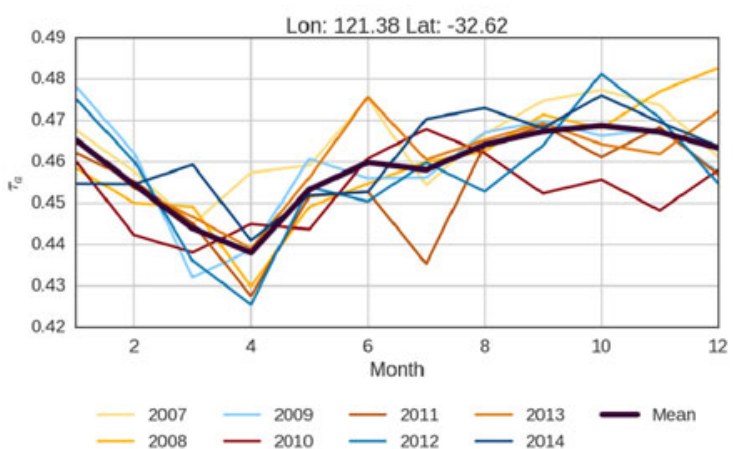

(f)

Fig. 6. Time series for $\tau_{a}$, LAI, and SSM (left figure) and monthly averages of $\tau_{a}$ (right figure) for: (a) and (b) interior Australia, (c) and (d) western Australia—croplands, and (e) and (f) western Australia—deciduous broadleaf forest. The locations of the grid points are depicted in Fig. 2.

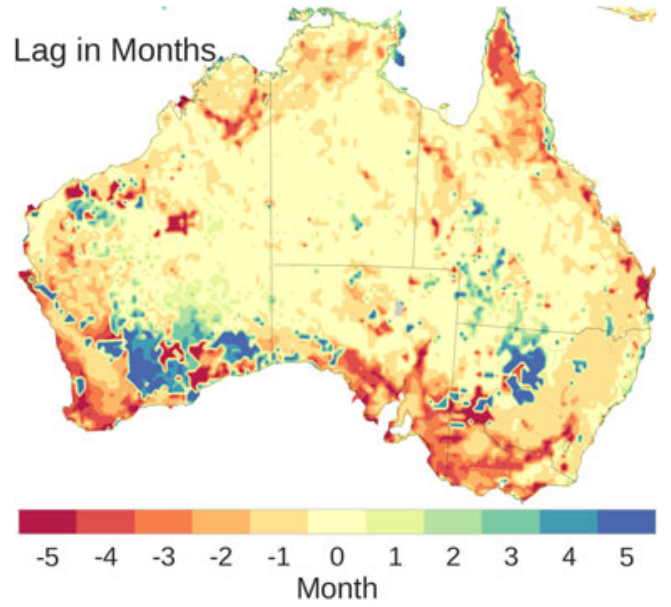

Fig. 7. Lag in months based on Spearman rank correlation between LAI and $\tau_{a}$. Red to orange colors indicate that $\tau_{a}$ lags behind LAI. months. This also explains the relatively low median $r_{s}$ for the croplands of 0.32. By correcting for the lag, $r_{s}$ increases to 0.59 for the croplands. The lag can be explained by the different vegetation characteristics represented by the two products. Since $\tau_{a}$ is more sensitive to the total water content in the vegetation, including the woody part, and LAI is sensitive to the green vegetation part, differences between them are to be expected on physical grounds. Over areas that are classified as bare soil, sparse vegetation, and grassland, grasses can bloom quickly after a rainfall event. If no woody vegetation is present, $\tau_{a}$ and LAI are both sensitive to the grasses only. Consequently, we do not observe a lag between $\tau_{a}$ and LAI. A lag was found by Jones et al. [15] between $\tau_{p}$ from AMSR-E observations and NDVI over the continental USA, which increased with increasing woody vegetation cover. The lag was attributed to the different rooting depths of grasses and woody vegetation. After a precipitation event, the rainfall is first available to grasses that 

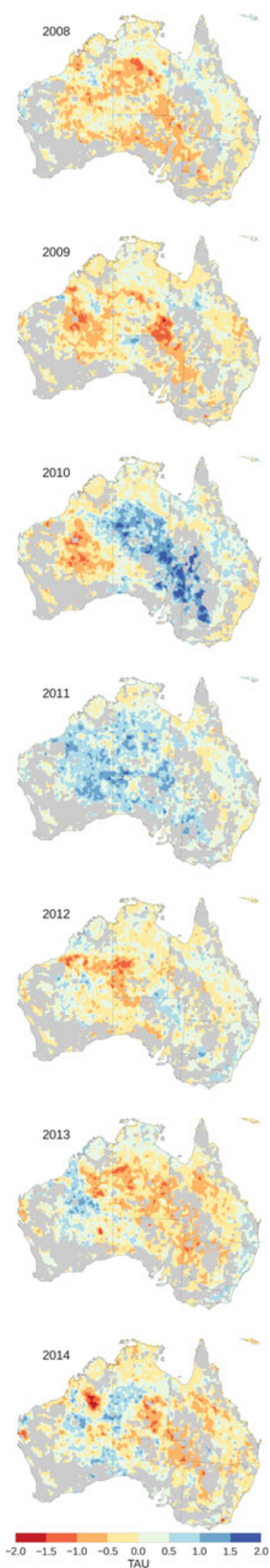
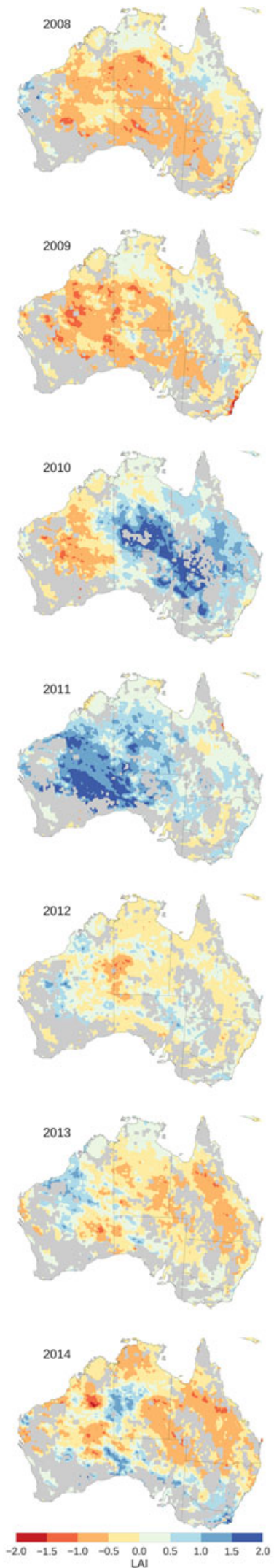
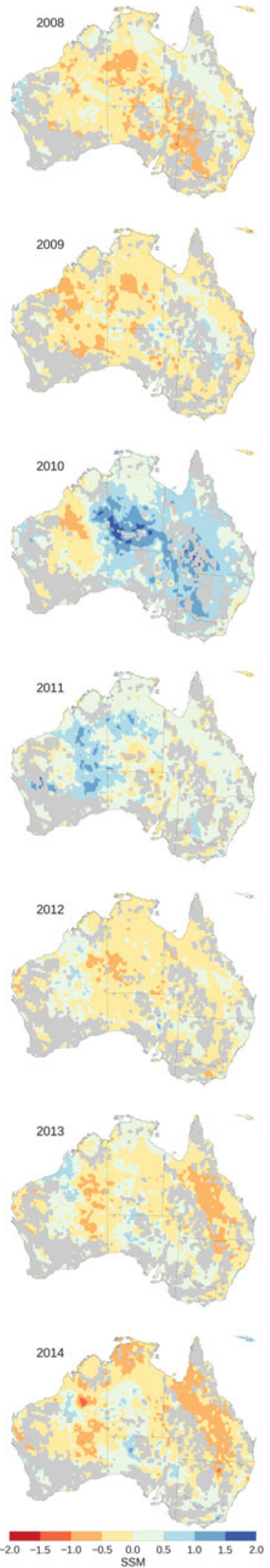

Fig. 8. Plots depicting the yearly differences from the mean over 2008-2014 for $\tau_{a}$ (left column), LAI (middle column), and SSM (right column). Higher (lower) than the ensemble average values are depicted in blue (red). 


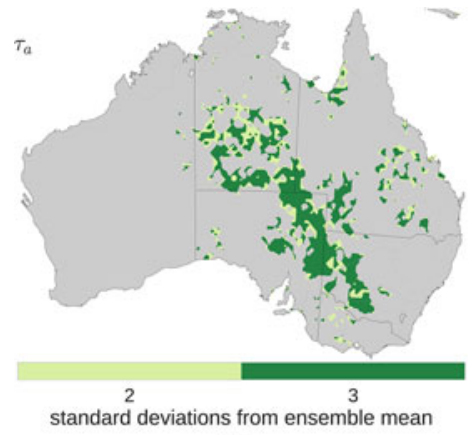

(a)

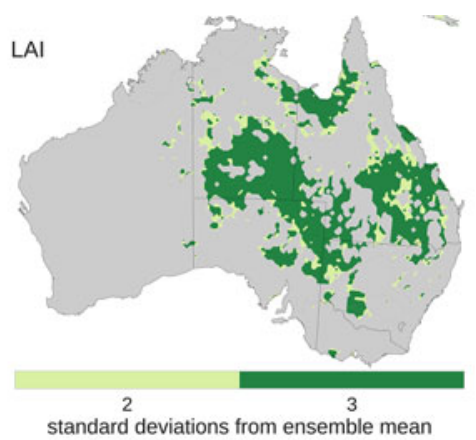

(b)

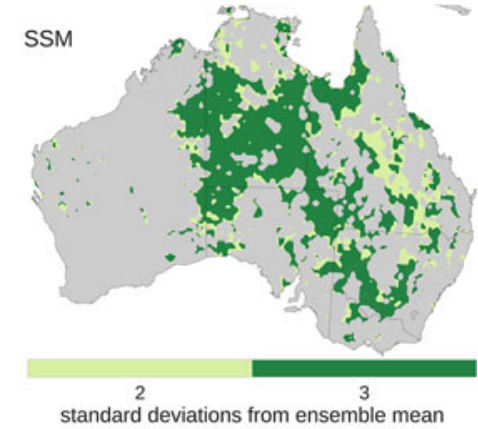

(c)

Fig. 9. Areas where a significant difference (three standard deviations above the ensemble mean) between the annual mean of 2010 and 2011 compared to the ensemble mean is found are indicated in green. Areas that are two standard deviations above the ensemble mean are depicted in yellow: (a) $\tau_{a}$, (b) LAI, and (c) SSM.

root in the upper soil layers. It was argued by Jones et al. [15] that the woody biomass will only accumulate when deeper soil layers are recharged. Since we observe no lag over bare soils, sparse vegetation, and grassland, and a lag of one to two months over areas with more woody vegetation cover this process could possibly also explain the observed lag between $\tau_{a}$ and LAI.

The analysis of temporal correlation of original time series and anomalies between $\tau_{a}$ and LAI shows that, apart from ephemeral lakes and rivers and deciduous broadleaf forest, $\tau_{a}$ follows LAI. This study confirms the hypothesis of Hahn et al. [3] that the variability that is seen in $\sigma^{\prime}$ is most likely driven by vegetation dynamics.

\section{B. Interannual Variability in $\tau_{a}$}

The calculation of $r_{\mathrm{sa}}$ showed that $\tau_{a}$ is sensitive to interannual variability in vegetation dynamics as represented by LAI in many grid points. Hence, we expect that yearly averages of $\tau_{a}$ and LAI show similar spatial patterns. Fig. 8 shows the yearly averages for $\tau_{a}$, LAI, and SSM, in areas where $r_{s}>0.2$. Overall, the patterns of the three products agree well. During the Millenium Drought (2007-2009), clear negative values can be seen. This is followed by two years of positive anomalies, which indicate an increase in vegetation and soil moisture. From 2012 onward, values decrease slowly every year, especially in eastern Australia. The clear positive anomalies in 2010 and 2011 observed for $\tau_{a}$, LAI, and SSM are focused in central and eastern Australia. SWA is characterized by below average values, which are also visible in the time series in Fig. 6(c). This corresponds to the observations reported in [12], where SWA suffered the driest year on record until then. The strongest anomalies are found in interior Australia, which typically does not receive much rainfall and vegetation is sparse. However, with precipitation events vegetation blooms, mainly grasses, and therefore relative changes are more extreme in interior Australia. Significant differences between the annual mean of 2010 and 2011 compared to the ensemble mean are found for all three products in interior Australia (see Fig. 9).

For all three products, a clear pattern from northwest Australia (NWA) to southeast Australia (SEA) can be seen in Fig. 8. This pattern coincides with cloud bands that form over the Indian Ocean northwest of NWA and bring moisture deep

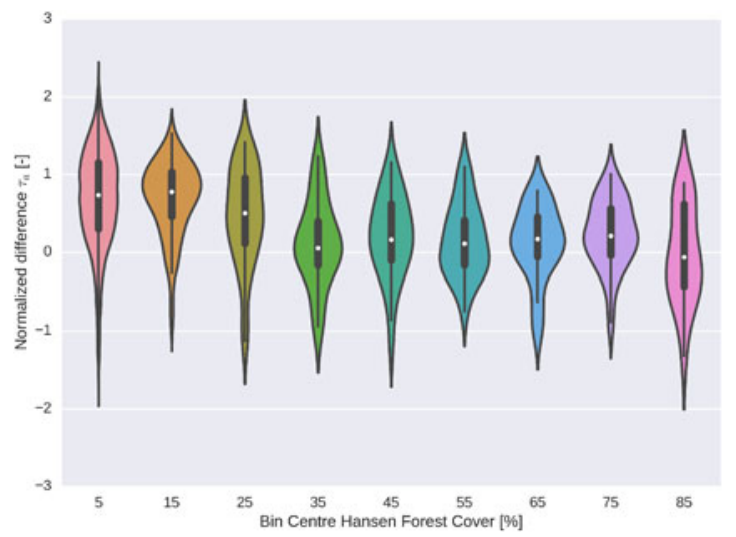

Fig. 10. Difference between normalized $\tau_{a}$ between the year 2008 and 2010 per grid point, binned to their respective percentage forest cover.

land inward to SEA. Cloud bands transport latent heat and moisture from tropical latitudes into higher latitudes and often trigger widespread and heavy rain over NWA and SEA [16]. This northwest to southeast pattern was also observed in the time series of rain gauges [17]. Variations in sea surface temperature over the Indian Ocean were found to be closely related to winter precipitation in a northwest to southeast band. Eastern rainfall was found to relate the best to sea surface temperature variations in the Pacific Ocean. It was also found by Ummenhofer et al. [18] that anomalous wet conditions were enhanced by precipitation brought by northwest cloud bands when La Niña co-occurs with a negative IOD phase. Hence, the clear northwest to southeast pattern that we observe could be related to precipitation brought by cloud bands, as an effect of the interaction of climate modes.

In more vegetated regions, $\tau_{a}$ and LAI do not vary as strongly as in interior Australia. Similar patterns were found in [19], where in semiarid drylands seasonality in $\tau_{p}$ was strong, but the interannual response was limited. This was explained by seasonal abundance in water, where variation in precipitation does not affect vegetation. This is depicted in Fig. 10, where the difference for every grid point between the yearly average of 2008, a year during the Millenium Drought, and 2010, during La Niña, is binned per percentage of forest cover. Here, the relative difference between the two years decreases with the increasing forest 
cover. This could indicate that total water content in vegetation changes less dramatically in more forested regions, and that $\tau_{a}$ is less sensitive to vegetation water content over forests than grasslands. This can also be observed in Fig. 9, in which the eastern parts of Australia LAI [see Fig. 9(b)] shows significant differences between the annual mean of 2010 and 2011 compared to the ensemble mean, but for $\tau_{a}$ [see Fig. 9(a)] this is limited to a smaller region.

\section{CONCLUSION}

This study assessed the ability of $\tau_{a}$ derived from ASCAT-A to capture interannual variability in vegetation dynamics. An improved estimation of model parameters in the TU Wien soil moisture algorithm allows for the retrieval of time series of $\tau_{a}$. We demonstrate that $\tau_{a}$ derived from ASCAT-A is related to vegetation dynamics, as observed in LAI. In forested regions, negative correlations between $\tau_{a}$ and LAI are observed, which are attributed to scattering mechanisms that are not accounted for in the current $\tau_{a}$ retrieval algorithm. Furthermore, dynamics of $\tau_{a}$ show distinct inter annual variability, as observed in LAI and SSM. For $\tau_{a}$, but also LAI and SSM, positive anomalies are observed in an area that extends from northwest to southeast Australia. This area is possibly related to the northwest cloud bands that form over the Indian Ocean, bringing precipitation land inward to southeast Australia. Due to its sensitivity to the woody part of the vegetation, $\tau_{a}$ shows a less pronounced increase in the north-east and east part of Australia.

This study confirms that variations in $\tau_{a}$ are related to vegetation dynamics. It demonstrates the added value of scatterometers to monitor land surface parameters. However, the problems that were encountered in forested regions show that further studies on backscatter mechanisms and how to account for them in scattering models is needed. The successive scatterometers onboard ERS-1, Metop-A, Metop-B, and in the future Metop$\mathrm{C}$ and Metop-SG SCA, provide a long-term dataset, which presents an opportunity to further study trends and interannual variability in vegetation and scattering mechanisms related to vegetation.

\section{ACKNOWLEDGMENT}

The product is based on SPOT/VGT $1 \mathrm{~km}$ data [(c) CNES and distributed by VITO]. The authors would like to thank the ESA Climate Change Initiative Land Cover Project (2014) for providing land cover data.

\section{REFERENCES}

[1] T. Melzer, "Vegetation modelling in WARP 6.0," in Proc. EUMETSAT Metereological Satellite Conf., Vienna, Austria, Sep. 2013.

[2] W. Wagner, G. Lemoine, M. Borgeaud, and H. Rott, "A study of vegetation cover effects on ERS scatterometer data," IEEE Trans. Geosci. Remote Sens., vol. 37, no. 2, pp. 938-948, Mar. 1999.

[3] S. Hahn, C. Reimer, M. Vreugdenhil, T. Melzer, and W. Wagner, "Dynamic characterization of the incidence angle dependency of backscatter using METOP ASCAT," IEEE J. Sel. Topics Appl. Earth Observ. Remote Sens. Scatterometer Special Issue, in press.

[4] M. Vreugdenhil, W. A. Dorigo, W. Wagner, R. A. M. de Jeu, S. Hahn, and M. J. E. van Marle, "Analyzing the vegetation parameterization in the TU-Wien ASCAT soil moisture retrieval," IEEE Trans. Geosci. Remote Sens., vol. 54, no. 6, pp. 3513-3531, Jun. 2016.
[5] M. Doubkova, V. Naeimi, W. Wagner, and G. Henebry, "On the ability of the ERS scatterometer to detect vegetation properties," in Proc. IEEE Int. Geosci. Remote Sens. Symp., 2009, vol. 3, pp. III-920-III-923.

[6] E. P. W. Attema and F. T. Ulaby, "Vegetation modeled as a water cloud," Radio Sci., vol. 13, no. 2, pp. 357-364, 1978. [Online]. Available: http:// dx.doi.org/10.1029/RS013i002p00357

[7] A. Ahlstrm et al., "The dominant role of semi-arid ecosystems in the trend and variability of the land $\mathrm{CO}_{2}$ sink," Science, vol. 348, no. 6237, pp. 895-899, May 2015. [Online]. Available: http://science.sciencemag. org/content/348/6237/895.short

[8] H. W. Linderholm, "Growing season changes in the last century," Agricultural Forest Meteorol., vol. 137, no. 12, pp. 1-14, Mar. 2006. [Online]. Available: http://www.sciencedirect.com/science/article/pii/ S0168192306000931

[9] A. D. Richardson, T. F. Keenan, M. Migliavacca, Y. Ryu, O. Sonnentag, and M. Toomey, "Climate change, phenology, and phenological control of vegetation feedbacks to the climate system," Agricultural Forest Meteorol., vol. 169, pp. 156-173, Feb. 2013. [Online]. Available: http://www. sciencedirect.com/science/article/pii/S0168192312002869

[10] V. Naeimi, K. Scipal, Z. Bartalis, S. Hasenauer, and W. Wagner, "An improved soil moisture retrieval algorithm for ERS and METOP scatterometer observations," IEEE Trans. Geosci. Remote Sens., vol. 47, no. 7, pp. 1999-2013, Jul. 2009.

[11] H. H. Hendon, E.-P. Lim, J. M. Arblaster, and D. L. Anderson, "Causes and predictability of the record wet east Australian spring 2010," Climate Dyn., vol. 42, nos. 5/6, pp. 1155-1174, 2014. [Online]. Available: http://link.springer.com/article/10.1007/s00382-013-1700-5

[12] A. I. J. M. van Dijk et al., "The millennium drought in southeast Australia (2001-2009): Natural and human causes and implications for water resources, ecosystems, economy, and society," Water Resources Res., vol. 49, no. 2, pp. 1040-1057, Feb. 2013. [Online]. Available: http:// onlinelibrary.wiley.com/doi/10.1002/wrcr.20123/abstract

[13] F. Baret et al., "GEOV1: LAI and FAPAR essential climate variables and FCOVER global time series capitalizing over existing products. Part1: Principles of development and production," Remote Sens. Environ., vol. 137, pp. 299-309, Oct. 2013. [Online]. Available: http://www. sciencedirect.com/science/article/pii/S0034425713000813

[14] J. T. Puckridge, F. Sheldon, K. F. Walker, and A. J. Boulton, "Flow variability and the ecology of large rivers," Marine Freshwater Res., vol. 49, no. 1, pp. 55-72, 1998. [Online]. Available: http://www.publish. csiro.au/?paper $=$ MF94161

[15] M. O. Jones, J. S. Kimball, L. A. Jones, and K. C. McDonald, "Satellite passive microwave detection of North America start of season," Remote Sens. Environ., vol. 123, pp. 324-333, Aug. 2012. [Online]. Available: http://www.sciencedirect.com/science/article/pii/S0034425712001575

[16] W. J. Wright, "Tropical-extratropical cloudbands and Australian rainfall: I. Climatology," Int. J. Climatol., vol. 17, no. 8, pp. 807-829, Jun. 1997.

[17] N. Nicholls, "Sea surface temperatures and Australian winter rainfall," J. Climate, vol. 2, no. 9, pp. 965-973, 1989.

[18] C. C. Ummenhofer et al., "What causes southeast Australia's worst droughts?" Geophysical Res. Lett., vol. 36, no. 4, pp. 1-5, 2009. [Online]. Available: http://onlinelibrary.wiley.com/doi/10.1029/2008GL036801/ full

[19] N. Andela, Y. Y. Liu, A. I. J. M. van Dijk, R. A. M. de Jeu, and T. R. McVicar, "Global changes in dryland vegetation dynamics assessed by satellite remote sensing: Comparing a new passive microwave vegetation density record with reflective greenness data," Biogeosciences, vol. 10, no. 10, pp. 6657-6676, 2013. [Online]. Available: http://www. biogeosciences.net/10/6657/2013/

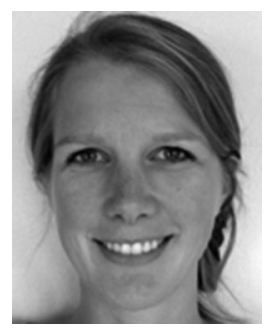

Mariette Vreugdenhil received the B.Sc. degree in earth sciences and the M.Sc. degree in applied environmental geosciences with an emphasis on remote sensing from Vrije Universiteit Amsterdam, Amsterdam, The Netherlands, in 2009 and 2011, respectively. Since 2012, she has been working toward the Ph.D. degree in remote sensing in the doctoral program on water resource systems at Vienna University of Technology, Vienna, Austria.

For her Master's Thesis, she participated in the calibration and validation campaign of ESA's SMOS satellite (AACES) in Australia. Her research interest is microwave remote sensing of soil moisture and vegetation, with focus on the parameterization of vegetation in soil moisture retrievals from both active and passive microwave remote sensing observations, and calibration and validation. She is responsible for the installation and maintenance of an in situ soil moisture network in Austria, which functions as a validation site for new soil moisture satellites. 


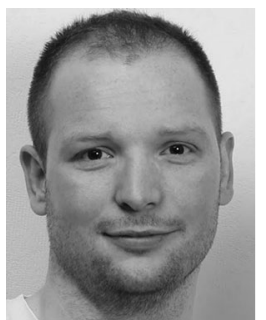

Sebastian Hahn was born in Vienna, Austria, in 1985. He received the B.Sc. degree in geodesy and geomatic engineering and the M.Sc. degree in geodesy and geophysics from Vienna University of Technology (TU Wien), Vienna, Austria, in 2009 and 2011, respectively.

Since April 2010, he has been a Project Assistant with the Research Group Remote Sensing, Department of Geodesy and Geoinformation, TU Wien. He is currently one of the key developers for the software package WARP (Soil Water Retrieval Package), which represents the implementation of the TU Wien soil moisture retrieval model. As a Developer, he is focused on software design, multiprocessing, model calibration, and algorithmic improvements, also in light of his Ph.D. studies started in 2011. His research interests include remote sensing over land using active microwave instruments, active soil moisture retrieval algorithms, software development, and validation of soil moisture products.

Thomas Melzer was born in 1968. He received the M.Sc. (Dipl.Ing.) degree in computer science and the Ph.D. (Dr.techn.) degree in pattern recognition and image processing from Vienna University of Technology (TU Wien), Vienna, Austria, in 1997 and 2002, respectively.

Since 2004, he has been with the Geo Department, TU Wien. He is also a Lecturer in statistical pattern recognition, image processing, and numerical optimization. His current research focuses on the extraction of physical and geometrical information from the laser and microwave backscatter signals.

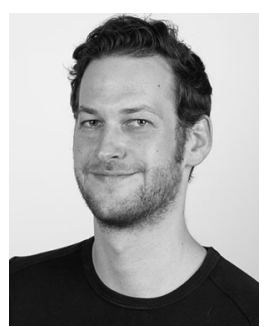

Bernhard Bauer-Marschallinger received the M.Sc. degree in geodesy and geophysics from the Technical University of Vienna (TU Wien), Vienna, Austria, in 2012, where he is currently working toward the Ph.D. degree in remote sensing.

Since 2009, he has been a Lecturer and a Researcher with the Department of Geodesy and Geoinformation, TU Wien. As part of the Remote Sensing Research Group, he has been involved in projects from ESA, EU FP7, Copernicus Global Land Services, and Austrian Research Promotion Agency (FFG). He is currently working on a new design of the Synthetic Aperture Radar (SAR) software engine in order to process the observations from the Sentinel-1 SARs, aiming for efficiency in storage and computing. His current research focuses on the preparation and exploitation of the satellite data for the retrieval of geophysical variables. Recently, he is working on the fusion of satellite observations from different spatial and temporal scales, and is also investigating long-term remote sensing observations in order to research on large-scale hydrology and climate change effects.

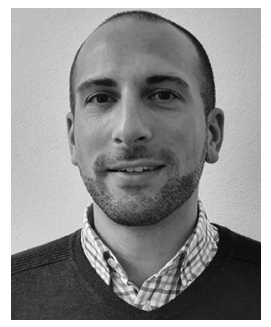

Christoph Reimer was born in Vienna, Austria, in 1985. He received the B.Sc. degree in geodesy and geomatics engineering and the M.Sc. degree in geodesy and geophysics with an emphasis on active microwave remote sensing from Vienna University of Technology (TU Wien), Vienna, Austria, in 2011 and 2014, respectively.

Since June 2011, he has been a Project Assistant with the Research Group Remote Sensing, Department of Geodesy and Geoinformation, TU Wien. He is part of the software development team of the soil moisture processing software WARP (Water Retrieval Package), which represents the implementation of the TU Wien soil moisture retrieval model. His research interests include radar remote sensing, radiometric calibration of spaceborne active microwave instruments, soil moisture retrieval algorithms, and the creation of a soil moisture climate data record.

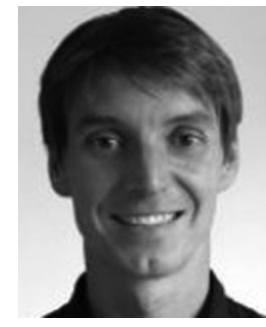

Wouter Arnoud Dorigo received the M.Sc. degree in physical geography with an emphasis on remote sensing from Utrecht University, Utrecht, The Netherlands, in 2000, and the Ph.D. degree in remote sensing from the Technical University of Munich, Munich, Germany, in 2008.

From 2002 to 2006, he was with the Imaging Spectroscopy Group, German Remote Sensing Data Center (DFD), German Aerospace Center (DLR). Since 2007, he has been a Researcher, a Lecturer, and a Scientific Project Co-ordinator with the Institute of Photogrammetry and Remote Sensing, Vienna University of Technology (TU Wien), Vienna, Austria. He has authored and coauthored more than 60 publications in refereed journal papers and conference proceedings. His research interest is remote sensing of soil moisture and vegetation, with focus on geophysical parameter retrieval through physical and semi-empirical methods, calibration and validation, process automation, up- and downscaling, image classification, data merging, and time series analysis. Using earth observation data, he tries to understand and quantify the dynamics and interactions of vegetation and the water cycle in a changing climate.

Mr. Dorigo was awarded the 2015 Science Award of the TU Wien for the water cycle in a changing climate.

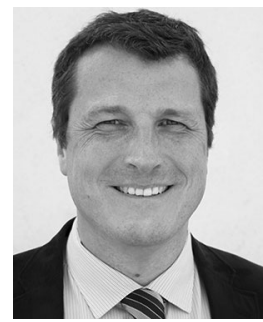

Wolfgang Wagner (M'98-SM'07) was born in Wels, Austria, in 1969. He received the Dipl.Ing. (M.Sc.) degree in physics and the Dr.techn. (Ph.D.) degree in remote sensing, both with excellence, from $\mathrm{Vi}$ enna University of Technology (TU Wien), Vienna, Austria, in 1995 and 1999, respectively.

In support of his Master's and Ph.D. studies, he received fellowships to carry out research at the University of Bern, Atmospheric Environment Service Canada, NASA Goddard Space Flight Center, European Space Agency, and the Joint Research Center of the European Commission. From 1999 to 2001, he was with the German Aerospace Agency (DLR). In 2001, he was appointed a Professor for remote sensing at TU Wien.

From 2008 to 2012, he was an ISPRS Commission VII President and from 2009 to 2011 an Editor-in-Chief of the Open Access Journal Remote Sensing. Since 2012, he has been the Head of the Department of Geodesy and Geoinformation, TU Wien. He is the cofounder and the Head of science of the Earth Observation Data Centre for Water Resources Monitoring. $\mathrm{He}$ is a member of the Science Advisory Groups for Sentinel-1 (ESA), METOP ASCAT, and METOP-SG SCA (EUMETSAT and ESA), and GCOS/GTOS/WCRP Terrestrial Observation Panel for Climate. His research interests include geophysical parameter retrieval techniques from remote sensing data such as scatterometry, SAR, and full-waveform airborne laser scanning, and application development. 